BLS 32, No 1 2006. DOI: http://dx.doi.org/10.3765/bls.v32i1.3475 (published by the Berkeley Linguistics Society and the Linguistic Society of America)

\title{
Noun Incorporation and Case: Evidence from Sakha
}

\author{
CHRISTOPHER A. STRAUGHN \\ University of Chicago
}

\section{On Sakha}

Sakha (also known as Yakut) is a typically Turkic language, featuring vowel harmony, a nominative-accusative case system, strict SOV word order with modifiers before modified, 'agglutinative' word formation with suffixing morphology, and a complex system of converbs to indicate mood and aspect. It is spoken in Russia in the Sakha Republic (formerly Yakutia), by approximately 380,000 people. Contacts with surrounding languages, mostly Tungusic and Paleosiberian, have introduced large numbers of loanwords into Sakha and have affected its grammar. As many of these languages feature noun incorporation (henceforth NI), it is reasonable to speculate that the NI-like phenomena found in Sakha developed from these contacts (Kirişçioğlu 1999).

\section{Introduction}

A characteristically non-Turkic feature of Sakha is the presence of nounincorporation-like phenomena, similar to the type exhibited in West Greenlandic Eskimo. Unlike traditional forms of NI, though, the form of NI found in Sakha causes alternation in case when the internal argument of the incorporating verb is conjoined to the verb, thereby disrupting normal assignment of accusative case. In order to explain the mechanics of this case alternation, I will invoke Bittner and Hale's analysis of case-assignment by means of a KP shell.

By analyzing the data in Sakha, I will show that while canonical NI is not present, the data still provides insights into the structure of the verb. By employing Bittner and Hale's analysis of case, I will show that the data in Sakha are best accounted for by positing a $\mathrm{D}+\mathrm{V}$ complex as the standard structure of transitive verbs in accusative languages. This analysis not only accounts for Sakha, but promises to account for a wide range of NI-like and light verb phenomena in a wide range of languages.

The behavior of the incorporating/light verb in Sakha is unique among Turkic languages, yet the analysis of this verb sheds light not only on the range of possibilities in Turkic language, but on the structure of the verb itself. 


\section{Christopher A. Straughn}

\section{The - $L A A$ - Suffix in Sakha}

Sakha possesses a verbalizing suffix $-L A A$ - which acts in certain cases similarly to an incorporating verb. This suffix derives from a Common Turkic morpheme $*-L \bar{A}$-, which is present in most, if not all other Turkic languages. As a result of vowel harmony and consonant assimilation, this verbalizer (which I represent using archiphonemes) is realized as sixteen different forms based on conditioning environment:

(1)

\begin{tabular}{|c|c|c|c|c|}
\hline \multicolumn{5}{|c|}{ CONSONANT ASSIMILATION } \\
\hline AFTER: & $1, \mathrm{~V}$ & $\begin{array}{l}\mathrm{p}, \mathrm{t}, \mathrm{c}, \mathrm{s}, \\
\mathrm{x}\end{array}$ & $\mathrm{r}, \mathrm{y}$ & $\mathrm{m}, \mathrm{n}, \mathrm{y}$ \\
\hline $\mathrm{a}, \ddot{\mathrm{i}}, \mathrm{u}$ & -laa- & -taa- & -daa- & -naa- \\
\hline $\mathrm{e}, \mathrm{i}, \ddot{u}$ & -lee- & -tee- & -dee- & -nee- \\
\hline o & -loo- & -too- & - doo- & -noo- \\
\hline$\ddot{0}$ & -löö- & -töö- & -döö- & -nöö- \\
\hline
\end{tabular}

The $-L A A$ - verbalizer is promiscuous, attaching to most non-verbs, including interjections, numerals, quantifying adverbs, question words, adjectives, temporal adverbs, and nouns. Examples below are from Vinokurova 2005 and Kirişçioğlu 1999.

(2) Interjections:

(2.1) ayïkka! 'interjection of pain'> ayikka-laa- 'to express pain'

(2.2) hay! 'interjection for driving cattle' > hay-daa- 'to drive cattle'

(3) Numerals:

(3.1) ikki 'two' > ikki-lee- 'to do two times'

(3.2) ikkis 'second' > ikkis-tee- 'to do a second time'

(4) Quantifying Adverbs:

(4.1) baçça 'this much' > baçça-laa- 'to do this much'

(4.2) oçço 'that much'> oçço-loo- 'to do that much'

(5) Question Words:

(5.1) tuox 'what?' > tuox-taa- 'to do what?'

(5.2) xanna 'where?' > xanna-laa- 'to go where?'

(6) Temporal Adverbs:

(6.1) erde 'early' > erde-lee- 'to do something early'

(6.2) urut 'before, previously'> urut-taa- 'to do something before something'

(7) Adjectives

(7.1) aççik 'hungry' > aççik-taa- 'to be hungry'

(7.2) kihil 'red' > kihil-laa- 'to be red, become red' 
(8) Nouns:

(8.1) ötüye 'hammer' > ötüye-lee- 'to hammer'

(8.2) oğo 'child'> oğo-loo- 'to babysit'

The resulting verbs are then treated as any other verb and are marked accordingly to tense, aspect, person ${ }^{1}$, etc.

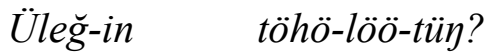

Work-2s.poss how.much-LAA-2sPST

'How much of your work have you done?'

$\begin{array}{ll}\text { Miexe } & \text { telefon-naa-bït } \\ \text { 1s.DAT } & \text { telephone-LAA-3s.hearsay } \\ \text { 'He supposedly called me.' }\end{array}$

Based on the data in (2)-(8) - LAA- appears to behave like a typical verbalizing morpheme that exhibits nothing unusual - certainly nothing syntactic in nature. Examine, however, the example provided below:

Sargï ŏgo-lor-u kïhïl, saharxay, küöx šarik-tar-daa-ta. Sargï child-PL-ACCred yellow blue balloon-PL-LAA-3sPST 'Sargy gave the children red, yellow, and blue balloons.'

It appears that the noun šarik 'balloon' is being modified by kihïl, saharxay, küöx 'red, yellow, blue'. Because adjectives always precede the noun they modify, 'red, yellow, blue' may modify neither 'children' nor 'Sargy'. And because the modifiers do not have an adverbial ending (in which case their forms would be kihilliik, saharxaydik, küöxtük) an adverbial reading, in which the entire verb is modified, is not possible. A third possibility is that 'red, yellow, blue' are merely nouns acting as objects of the verb šarik-tar-da-, but (12) rules out this possibility, as it is not possible to assign the optional accusative case to these words:

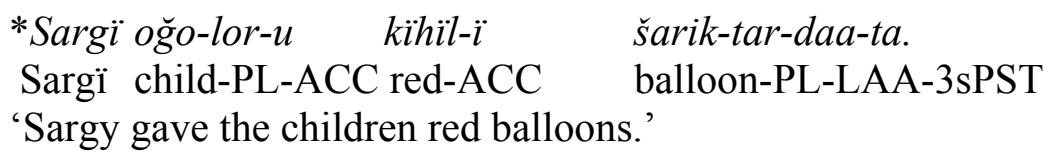

Such a construction not only improperly assigns accusative case to 'red', but assigns that case to both the theme and goal of the sentence. The only remaining interpretation is that the verbalized noun is receiving external modification.

While the evidence in (17) and (18) strongly suggests the presence of NI-like phenomena, further examination is necessary before claiming that every instance

\footnotetext{
${ }^{1}$ Note that only the subject is marked on verbs in Sakha.
} 


\section{Christopher A. Straughn}

of verbalization in Sakha is NI. To that end, I present below Vinokurova's 2005 semantic breakdown of possible results of application of the $-L A A$ - suffix:

(13)

\begin{tabular}{l|l|l|l} 
MEANING & MoDIFIED N & PLURAL N & TRANSITIVE V \\
\hline a. Provide w/ N & Y & Y & Y \\
\hline b. Go toward N & Y & N & N \\
\hline c. Use N as instrument & N & N & Y \\
\hline d. Remove N & N & N & Y \\
\hline e. Make/Hunt/Gather N & N & N & N \\
\hline f. Look after N & N & N & Y \\
\hline g. Consume N & N & N & Y \\
\hline h. Imitate/Act/Work as N & N & N & Y \\
\hline i. Play N & N & N & N \\
\hline j. 'Weather' N & N & N & N \\
& & \multicolumn{2}{|l}{}
\end{tabular}

Based on the data in (13), we see that in certain cases the verbalized noun may be modified and/or plural. These cases (Types a. \& b.) and only these cases are consistent with phenomena associated with NI. The second type however, reveals little compared to the first, so the example provided below will be the only mention made of this second type:

Ookko ïraas djie-lee-te.

Ookko clean house-LAA-3sPST

'Ookko went to a clean house.'

The form in (14) exhibits the most interesting aspect of the second - the 'go toward' type verb: the ability of the verbalized noun to be modified by an external adjective. But because these forms exhibit none of the case alternations found in the first - the 'provide with' forms, I will not focus on them further.

\section{But is it NI?}

Up to this point, the nature of the -LAA- phenomenon in Sakha has been left ambiguous. The history of noun incorporation is contentious, with most authors defining the term in a slightly different manner. In Sakha it is clear that $-L A A$ incorporates phonologically and morphologically, but syntactic incorporation is harder to prove.

The evidence for phonological incorporation of the noun $+L A A$ complex lies in the complex system of vowel harmony and consonant assimilation that gives $-L A A$ - one of its sixteen forms. The disharmonic form in (15) never surfaces:

*šarik-tar-nöö-

balloon-PL-LAA 
While the term incorporation may be inappropriate here, a term such as 'unified' adequately describes the fact that the noun plus $-L A A$ - are a single phonological unit.

Evidence for morphological incorporation comes from the inability of the syntax to alter the noun $+L A A$ complex. For example, question particles (which behave like focus markers in Sakha) may not be inserted between the noun and $-L A A-$ :

$$
\begin{aligned}
& \text { *Ayaal küter-ni külüüs du-laa-ta? } \\
& \text { Ayaal muskrat-ACC key Q.Part-LAA-3sPST } \\
& \text { 'Did Ayaal give the muskrat a key?' }
\end{aligned}
$$

Instead, the question particle treats the verb as a single unit and follows it:

$$
\begin{array}{ll}
\text { Ayaal küter-ni külü̈̈s-tee-te } & d u ? \\
\text { Ayaal muskrat-ACC key-LAA-3sPST } & \text { Q.Part } \\
\text { 'Did Ayaal give the muskrat a key? } &
\end{array}
$$

(Notably, in this sort of construction, the semantic vacuity of -LAA- prevents it from being the object of focus. In (17), key is the only possible object of focus.)

Other evidence for the morphological unity of the noun $+L A A$ complex comes from passive constructions. In standard passives in Sakha, which involve a full verb plus its arguments, only the lowermost argument may be raised to become the subject of the sentence. The second, or indirect object may not be raised in passivization. In $-L A A$ - constructions, however, the noun attached to - LAA- may never be raised; only the indirect object, which receives accusative case in standard transitive constructions, may be raised:

$$
\begin{aligned}
& \text { *Saharxay, küöx šarik-tar ŏgo-lor-?? -LA-n-nI-lAr. } \\
& \text { Yellow blue balloon-PL child-PL-Case?-LAA-PASS-3SPST-PL } \\
& \text { 'Yellow and blue balloons were given to the children.' }
\end{aligned}
$$

$$
\begin{aligned}
& \text { Ŏgo-lor saharxay, kü̈x } \quad \text { sarik-tar-la-n-nï-lar. } \\
& \text { Child-PL yellow blue balloon-PL-LAA-PASS-3sPST-PL } \\
& \text { 'The children were given yellow and blue balloons.' }
\end{aligned}
$$

Likewise, the noun attached to $-L A A$ - may not be raised for the purposes of topicalization or separated from - $L A A$ - in any other way.

Syntactic incorporation is somewhat more difficult to prove, as what occurs in Sakha is either inconsistent with or difficult to reconcile with traditional views on noun incorporation. Mithun, for example, states that "[i]n incorporating languages, a verb minus its I[ncorporated] N[oun] is still a well formed verb..." (1986:32). Sadock's interpretation of similar phenomena in West Greenlandic Eskimo as NI, however, supports the view of the phenomena in Sakha as NI. In West 


\section{Christopher A. Straughn}

Greenlandic, incorporating verbs are in a distinct class from ordinary verbs. For example, the standard term for 'to eat' is neri-, where as the incorporating form is -tor- (Sadock 1980:309). Sakha's - LAA- resemblance to West Greenlandic is somewhat tenuous, though, as Sakha possesses only the one incorporating verb, whereas West Greenlandic has about one hundred.

Baker's take on NI is more theoretically based. According to Baker, incorporation is present if a noun (typically the direct object) undergoes syntactic movement and unifies with the verb:

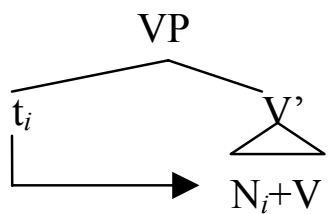

Adding to the support for Baker's approach is the statement that "Noun Incorporation NPs do not need to have Case" (1988:129), which is consistent with the data in Sakha. The 'incorporated' NP in Sakha receives no case, and, as in the cases of Eskimo and Niuean discussed by Baker, the cases of other arguments are altered. Baker writes off these case alternations to a "Case absorption" effect,' but is not explicit with regards to the exact mechanics of this operation (1988:129).

In order to better resolve the case alternations in Sakha, I turn to Bittner and Hale's analysis of case.

\section{Bittner and Hale's System of Case}

Among the most accepted aspects of Bittner and Hale's system of case is the presence of a K-head above nominals which acts as the morphological manifestation of case. Under this system, the $\mathrm{K}$-head is parallel to $\mathrm{C}$, the clausal head, the D-head is parallel to T or I, the tense/inflectional head, and the lexical $\mathrm{N}$ head is parallel to the lexical V head (1996:7). These relations are further illustrated in (21) below:
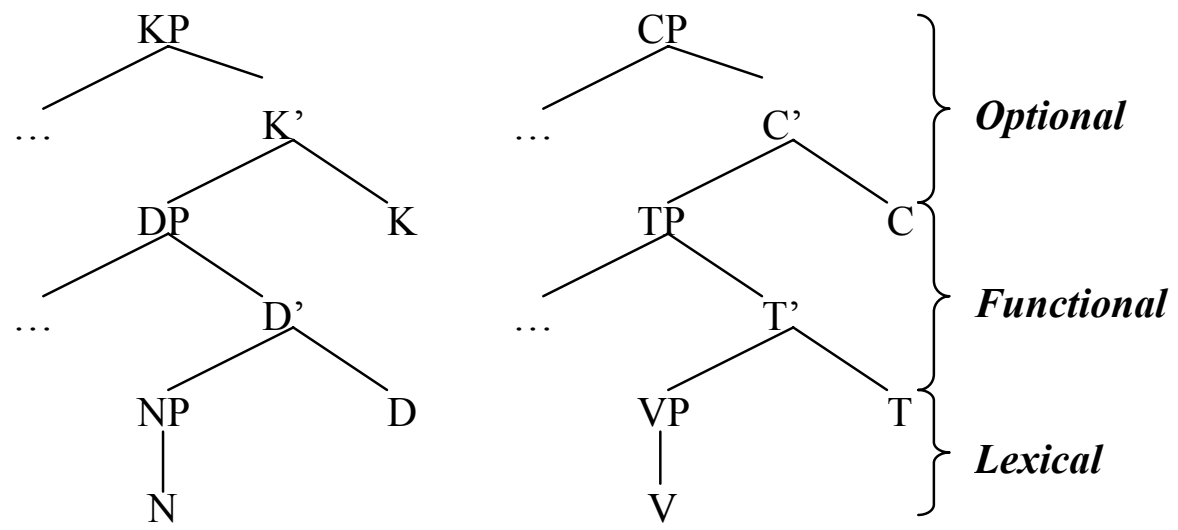
Under this system, the K-head will manifest itself (in some cases, at least) as an adposition. In Sakha, this supposition holds true, as case is marked as a clitic on the last element of a DP (which is always the noun):

$$
\text { Sargï [KР [DР oğo-lor }]-\boldsymbol{g o}] \quad\left[{ }_{\mathrm{KP}}[\mathrm{DP} \text { küöx šarik-tar]-nï] bier-de. }\right.
$$
Sargi [ ${ }_{\text {KP }}[\mathrm{DP}$ child-PL]-DAT] [KР[DP green balloon-PL]-ACC] give-3sPST 'Sargy gave the children green balloons.'

As shown in (21), however, a K-head is not always present. Where case is not traditionally marked, as in nominative or absolutive nominals, $\mathrm{K}$ is not present.

Case under this system is divided into structural case and inherent case, where structural case is a syntactically assigned case (accusative or ergative) and inherent case is that case which is assigned by some inherent case feature in the assigner (as with dative or ablative objects). In order for the K-head to be filled, a Case-competitor must be present. A Case-competitor is defined, then, as the following:

(23) $\gamma$ is a Case-competitor for an argument $\beta$, iff $\gamma$ is a $\mathrm{K}$-less nominal which is in a chain with a co-argument, or a pseudo co-argument, or $\beta$ (1996:43).

The nominative-accusative array in Sakha is summed up in Bittner and Hale's statement of direct case realizations:

(24) If $\alpha$ Case-binds an overt empty-headed KP $\beta$, then the empty $K$ of $\beta$ is realized as ACC, if $\alpha$ is V and has an adjoined D (1996:11).

The conditions for case binding are given later:

(25) Let $\alpha$ be a head which delimits a small clause and let $\beta$ be an argument. Then $\alpha$ Case-binds $\beta$, and $\beta$ 's head, iff

(i) $\quad \alpha$ locally c-commands $\beta$;

(ii) $\quad \alpha$ governs a Case-competitor for $\beta$ (1996:18)

As part of these case relations, Bittner and Hale posit a D-head attached to the verb in nominative accusative languages. A standard array is shown below:

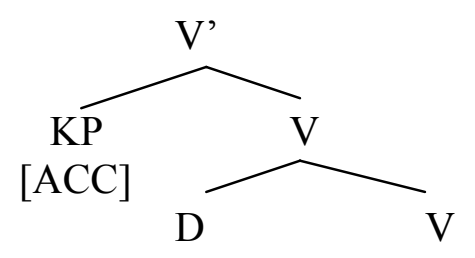




\section{Christopher A. Straughn}

The D-head attached to the verb acts as a Case-competitor for the nominal receiving accusative case. Other cases (e.g. dative, instrumental, ablative) are assigned by language specific conventions based on position within the clause. Methods for assigning case in ergative, split ergative, or three-way case systems are outlined by Bittner and Hale as well, but a full discussion of those cases is beyond the scope of this paper.

A point not fully elaborated upon by Bittner and Hale regarding the proposed $\mathrm{D}+\mathrm{V}$ complex is that this complex, once formed, is a single morphological unit. Bittner and Hale compare the D-head proposed for the verbal complex to the antipassive morpheme in ergative languages. Just as the antipassive morpheme may not undergo any of the sorts of movements allowed of standard verbal arguments, neither may the D-head in accusative languages move.

\section{Implications for Sakha}

The system of case proposed by Bittner and Hale provides a new way to examine the $-L A A$ - morpheme in Sakha. I propose that $-L A A$ - is a deficient verb that does not already possess an attached D-head. Accordingly, the first argument selected for by $-L A A$-, the theme, merges without a $\mathrm{K}$-head and therefore may not receive case. The next argument, the goal, possesses a K-head however, and a similar array to (27) results:

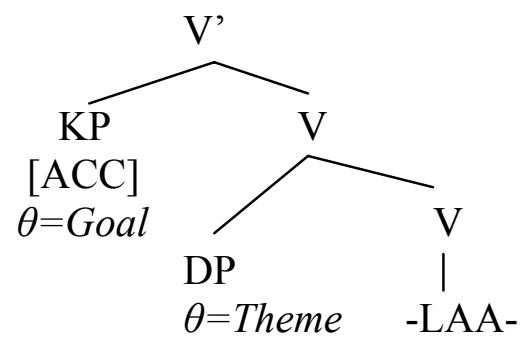

As applied to a full sentence, the result is as shown in (28):

$$
\begin{aligned}
& \text { [DP Sargi] [KP[DP ŏgo]-nu] [v[DP kïhïl, küöx šarik-tar]-daa-ta.] } \\
& \text { Sargi child-ACC red, blue balloon-PL-LAA-3sPST } \\
& \text { 'Sargy gave the child red and blue balloons.' }
\end{aligned}
$$

As noted previously, Bittner and Hale do not allow for the $\mathrm{D}+\mathrm{V}$ complex to be separated, as that would result in the raising of the antipassive morpheme or transitivizing morphology. Similarly, Sakha does not allow the D in the D+V constructions to separate, as that would result in the stranding of the deficient $-L A A$ - verb.

While it appears that Bittner and Hale's system of case merely provides an explanation for the data in Sakha, the data in Sakha in turn support Bittner and Hale. Traditional methods of case assignment fail to account for the lack of case 
on the lowest argument and the presence of accusative, rather than dative case on the indirect object, as shown in (29):

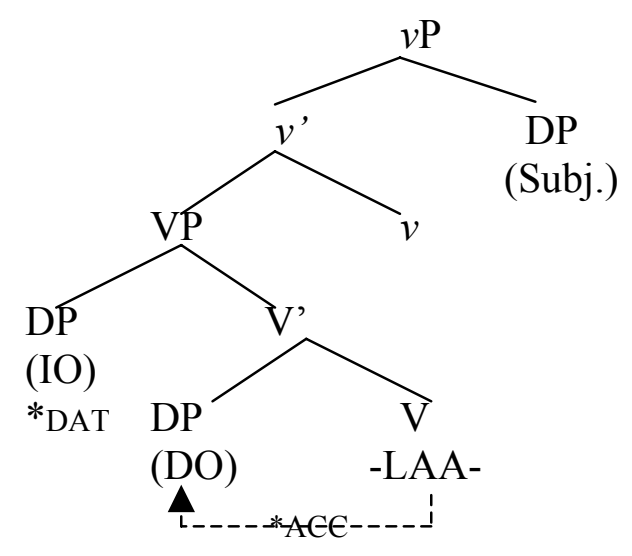

By distinguishing between nominals with and without K-shells, Bittner and Hale resolve the dilemma that would arise when traditional systems of case assignment attempt to describe Sakha, namely, what prevents the direct object from receiving accusative case? By allowing the presence or absence of a K-head, this dilemma is avoided under Bittner and Hale's case system.

\section{Conclusions}

Based on Baker's movement-based definition, the phenomena in Sakha are not NI. Although morphology and phonology indicate some sort of union between -LAAand its arguments, no syntactic movement occurs. Given the contentious history of NI, though, it seems appropriate to examine other languages considered to have NI to see if the $\mathrm{D}+\mathrm{V}$ approach is more fruitful.

With regards to other Turkic languages, the phenomena in Sakha are unique. Compare the form used previously with the ungrammatical form in Uzbek:

(30) Sakha

Sargï oğo-lor-u kïhïl, saharxay, küöx šarik-tar-daa-ta. Sargi child-PL-ACCred yellow blue balloon-PL-LAA-3sPST 'Sargy gave the children red, yellow, and blue balloons.'

(31) Uzbek

*Sargi og'il-lar-ni qizil, sariq, va ko'k sharik-lar-la-di. Sargy child-PL-ACCred yellow and blue balloon-PL-la-3sPST 'Sargy gave the children red, yellow, and blue balloons.'

The equivalent form in Uzbek is ungrammatical because of the external modification of 'balloon' by the color adjectives and the pluralization of 'balloon' before the addition of the verbalizing -la- morpheme. 


\section{Christopher A. Straughn}

However, there is promise in the analysis of other phenomena in Turkic using Bittner and Hale's analysis to examine light verbs. Most Turkic languages possess

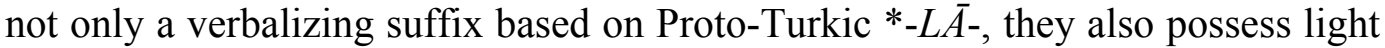
verbs, as shown in the examples below:

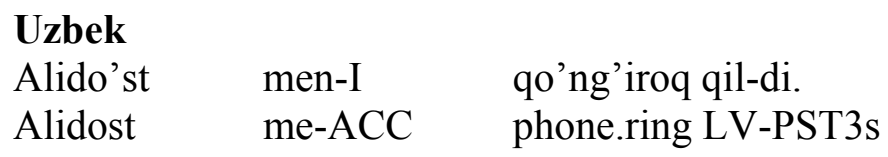

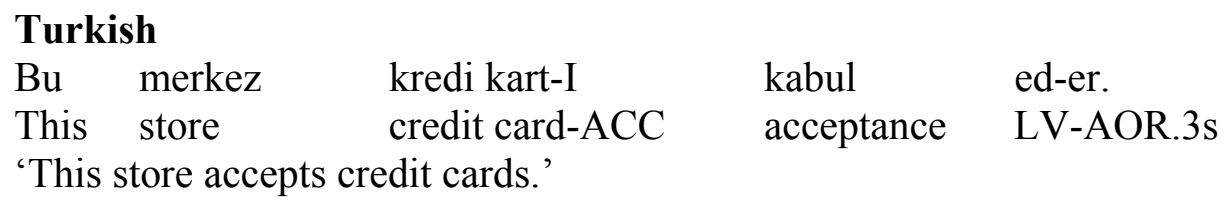

Before analyzing these and other light verbs as $\mathrm{D}+\mathrm{V}$ complexes further examination is necessary.

By analyzing data from Sakha and implementing Bittner and Hale's system of case assignment, it has been shown that Sakha possesses a form of NI unlike that of any other Turkic language, and that Bittner and Hale's system is required to account for it. The case alternations in Sakha, along with the possibility of modification of the incorporated noun provide evidence that there is, indeed, a D adjoined to the verb.

\section{References}

Baker, Mark C. 1988. Incorporation: A Theory of Grammatical Function Changing. Chicago: UC Press.

Bittner, Maria and Ken Hale. 1996. The Structural Determination of Case and Agreement. Linguistic Inquiry 27:1-95.

Kirişçioğlu, M. Fatih. 1999. Saha (Yakut) Türkçesi Grameri. 2nd ed. Atatürk Kültür, Dil ve Tarih Yüksek Kurumu 594. Ankara: Türk Dil Kurumu.

Mithun, Marianne. 1986. On the Nature of Noun Incorporation. Language 62:3238.

Sadock, Jerrold M. 1980. Noun Incorporation in Greenlandic: A Case of Syntactic Word Formation. Language 56:300-319.

Vinokurova, Nadezha. 2005. Lexical Categories and Argument Structure: A Case Study with Reference to Sakha. Diss., Universiteit Utrecht. 
Christopher A. Straughn

University of Chicago

Department of Linguistics

1010 E. $59^{\text {th }}$ St.

Chicago, IL 60637-1512

straughn@uchicago.edu 